\title{
Trends in standardized mortality among individuals with schizophrenia, 1993-2012: a population-based, repeated cross-sectional study
}

\author{
Evgenia Gatov MPH, Laura Rosella PhD, Maria Chiu PhD, Paul A. Kurdyak MD PhD
}

Cite as: CMAJ 2017 September 18;189:E1177-87. doi: 10.1503/cmaj.161351

See related article at www.cmaj.ca/lookup/doi/10.1503/cmaj.171010

CMAJ Podcasts: author interview at https://soundcloud.com/cmajpodcasts/161351-res

Visual abstract available at www.cmaj.ca/lookup/suppl/doi:10.1503/cmaj.161351/-/DC2

\section{ABSTRACT \\ BACKGROUND: We examined mortality time trends and premature mortality among individuals with and without schizophrenia over a 20 -year period.}

METHODS: In this population-based, repeated cross-sectional study, we identified all individual deaths that occurred in Ontario between 1993 and 2012 in persons aged 15 and over. We plotted overall and cause-specific age- and sexstandardized mortality rates (ASMRs), stratified all-cause ASMR trends by sociodemographic characteristics, and analyzed premature mortality using years of potential life lost. Additionally, we calculated mortality rate ratios (MRRs) using negative binomial regres- sion with adjustment for age, sex, income, rurality and year of death.

RESULTS: We identified 31349 deaths among persons with schizophrenia, and 1589902 deaths among those without schizophrenia. Mortality rates among people with schizophrenia were 3 times higher than among those without schizophrenia (adjusted MRR 3.12, 95\% confidence interval 3.06-3.17). Allcause ASMRs in both groups declined in parallel over the study period, by about $35 \%$, and were higher for men, for those with low income and for rural dwellers. The absolute ASMR difference also declined throughout the study period (from 16.15 to 10.49 deaths per 1000 persons). Cause-specific ASMRs were greater among those with schizophrenia, with circulatory conditions accounting for most deaths between 1993 and 2012, whereas neoplasms became the leading cause of death for those without schizophrenia after 2005. Individuals with schizophrenia also died, on average, 8 years younger than those without schizophrenia, losing more potential years of life.

INTERPRETATION: Although mortality rates among people with schizophrenia have declined over the past 2 decades, specialized approaches may be required to close the persistent 3-fold relative mortality gap with the general population.
M

ortality is a marker for the performance of the health care system. ${ }^{1}$ Over the past several decades, life expectancy has grown substantially in developed countries, ${ }^{2}$ largely because of increasing health promotion, public health interventions and improvements in the management of chronic disease. Yet individuals with a diagnosis of severe mental illness, such as schizophrenia, live shorter lives than people without psychiatric illness, ${ }^{3-5}$ despite often dying of the same physical illnesses. ${ }^{3}$ This suggests that they have not benefited from the public health strategies that have led to reduced mortality more generally. ${ }^{6}$ Although studies in
Canada and the United States have reported elevated mortality rates among patients with schizophrenia, ${ }^{7,8}$ time trends in all-cause and cause-specific mortality have not been explored. Determining whether there are concerning trends over time, and whether there are specific medical conditions that account for elevated mortality, will help to focus future interventions.

There is more evidence about mortality trends among individuals with severe mental illness than among individuals with schizophrenia specifically. Some European and Australian studies have recorded a widening mortality disparity between 
those with and without severe mental illness, ${ }^{9-11}$ whereas evidence from other, mainly Nordic, countries suggests a trend of declining mortality ${ }^{12}$ and a persistent relative mortality gap..$^{13,14}$ However, these studies are not generalizable to a population of individuals with schizophrenia because they encompassed diagnoses such as bipolar disorder and major depression, and typically used a single psychiatric hospital admission to identify cases. Using hospital admission for case ascertainment misses individuals managed in ambulatory settings and biases the sample toward greater severity, underestimating the prevalence and overestimating the mortality burden of severe mental illness. ${ }^{11-13,15}$ Mortality in more restricted populations of patients with schizophrenia is likely to be different from that in more heterogeneous populations with severe mental illness, because individuals with schizophrenia have a more chronic course of illness, ${ }^{16}$ more cognitive and functional impairment ${ }^{17}$ and likely a longer-term exposure to antipsychotics known to be associated with higher risk of diabetes mellitus. ${ }^{18}$ Thus, investigating the mortality trends of individuals with schizophrenia is crucial for determining whether they have experienced the same health improvements as the general population or whether other approaches are required to address their unique needs.

In this study, we exploited population-based mortality data for a 20-year period and used a validated method of accurately identifying every resident within the population who had a diagnosis of schizophrenia to report on all-cause and cause-specific relative and absolute mortality trends, as well as on premature mortality, among individuals with and without schizophrenia in Ontario, Canada.

\section{Methods}

\section{Setting, design and study population}

This repeated, cross-sectional study examined all Ontario adults with and without schizophrenia annually from Jan. 1, 1993, to Dec. 31, 2012. We used a validated algorithm to detect all cases of schizophrenia and schizoaffective disorder in Ontario from linked, population-level health administrative data available at the Institute for Clinical Evaluative Sciences (ICES). ${ }^{15}$ We ascertained cases on the basis of a single hospital admission within 12 months or 3 physician visits within 36 months (sensitivity 96.5\%, specificity $57.1 \%) .{ }^{15}$ Psychiatric hospital admissions before 2005 were captured in the Canadian Institute for Health Information (CIHI) Discharge Abstract Database, using the International Statistical Classification of Diseases and Related Health Problems, 10th revision (ICD-10) codes F20 and F25; hospital admissions from 2005 onward were captured in the Ontario Mental Health Reporting System using diagnosis 295 from the Diagnostic and Statistical Manual of Mental Disorders, 4th edition. We identified physician service claims from Ontario Health Insurance Plan data, which contain patient diagnostic codes for physician visits and consultation billings (specifically code 295). ${ }^{15}$ We examined all deaths that occurred each year among cases and non-cases through linkage to the Office of the Registrar General - Deaths vital statistics data set, which contains primary and intermediate causes of death (according to the International Classification of Diseases, 9th Revision [ICD-9] and
ICD-10-CA). We excluded individuals aged $0-14$ years, given the low likelihood of a valid schizophrenia diagnosis in this age group, ${ }^{19}$ and those for whom cause of death was not available.

\section{Outcomes}

To enable analyses over time, we enriched the data for the most responsible cause of death by creating a single ICD-9 variable based on $\mathrm{CIHI}$ conversion tables. In addition to all-cause mortality, we examined cause-specific mortality from natural and unnatural causes, ${ }^{8}$ adapted from the World Health Organization ${ }^{20}$ (Appendix 1, available at www.cmaj.ca/lookup/suppl/doi:10.1503/cmaj. 161351/-/DC1): diseases of the cardiovascular or circulatory system; neoplasms; diseases of the respiratory system; and metabolic, nutritional, immunity, endocrine and digestive conditions. Unnatural deaths were classified as suicide or accidental deaths. Denominators for the Ontario population were obtained from Statistics Canada population census files. All data sets were linked at the individual level using unique encoded identifiers and were analyzed at ICES.

\section{Covariables}

We captured age, sex, area-based income quintiles, and urban or rural dwelling using census information, attributed to individuals according to year of death, such that the 1991 census was used for 1993, 1996 census for 1994-1998, and so on. Area-based income was ascertained at the level of dissemination areas, the smallest available geographic census area. Current-day geographic boundaries were used to match individual postal code to geographic category.

\section{Statistical analysis}

We plotted (with tests for linear trend) all-cause and causespecific age- and sex-standardized mortality rates (ASMRs) from 1993 to 2012 for those with and without schizophrenia (standardized to the 2006 Ontario population using the direct method). ${ }^{21}$ We assessed absolute within-group differences and relative declines throughout the study period, expressed as percentages of the 1993 rates, and calculated between-group absolute and relative differences. To investigate whether all-cause and causespecific mortality time trends varied according to schizophrenia status, we modelled mortality rates for those with schizophrenia, relative to those without schizophrenia, using negative binomial regression models adjusted for age, sex, income quintile, rural dwelling and year of death (as a linear predictor), and then tested an interaction term between schizophrenia status and time. We report adjusted mortality rate ratios (MRRs), with corresponding 95\% confidence intervals (Cls), and temporal trends, expressed as the average annual percent change (the effect of year in the model). We further stratified all-cause ASMRs by sex, area-level income, and urban or rural dwelling.

Given that the prevalence of schizophrenia remained relatively stable over time, ${ }^{22}$ we conducted a post hoc sensitivity analysis to examine the extent of ascertainment bias that may have occurred because of an unequal accrual period for casefinding between 1993 and 2012. Because the denominator for 2012 was based on more than 20 years of case ascertainment, we 
applied the prevalence of schizophrenia in that year (about 1\%) to all denominators in the study period and repeated the process for numerators to obtain crude mortality rates.

We examined premature mortality by looking at age at time of death and analyzing years of potential life lost (YPLL), which measures the years not lived by each individual who died before age $75 .{ }^{23}$ The numerator was the sum of all YPLL, which was determined by computing, for each age group, the difference between 75 and the median age at death and multiplying that difference by the number of deaths. ${ }^{23}$ This calculation weights deaths at younger ages more heavily (i.e., the younger the age at death, the greater the numerator). The denominator consisted of individuals between the ages of 15 and 75 years. ${ }^{24}$ The resulting rates were then age- and sex-standardized to enable betweengroup comparisons.

All statistical analyses were conducted using SAS version 9.3.

\section{Ethics approval}

Ethics approval for this study was obtained from the Research Ethics Board at Sunnybrook Health Sciences Centre.

Table 1: Sociodemographic and clinical characteristics of individuals with and without schizophrenia who died in 1993

\begin{tabular}{|c|c|c|c|c|c|c|}
\hline \multirow[b]{2}{*}{ Characteristic } & \multicolumn{3}{|c|}{ Individuals without schizophrenia } & \multicolumn{3}{|c|}{ Individuals with schizophrenia } \\
\hline & $\begin{array}{c}\text { No. }(\%) \text { of } \\
\text { deaths }\end{array}$ & $\begin{array}{c}\text { Population 15-105 } \\
\text { yr, no. (\%) }\end{array}$ & $\begin{array}{l}\text { Crude rate per } 1000 \\
\qquad(95 \% \mathrm{Cl})\end{array}$ & $\begin{array}{l}\text { No. }(\%) \text { of } \\
\text { deaths }\end{array}$ & $\begin{array}{c}\text { Population 15-105 } \\
\text { yr, no. (\%) }\end{array}$ & $\begin{array}{l}\text { Crude rate per } 1000 \\
\qquad(95 \% \mathrm{Cl})\end{array}$ \\
\hline Overall & $72068(100)$ & $8793478(100)$ & $8.20(8.14-8.26)$ & $830(100)$ & 34338 (100) & $24.17(22.55-25.87)$ \\
\hline \multicolumn{7}{|l|}{ Age group, $y r$} \\
\hline $15-24$ & $732(1.0)$ & $1494489(17.0)$ & $0.49(0.45-0.53)$ & $13(1.6)$ & $2240(6.5)$ & $5.80(3.09-9.92)$ \\
\hline $25-34$ & $1265(1.8)$ & $1943429(22.1)$ & $0.65(0.62-0.69)$ & $62(7.5)$ & $7991(23.3)$ & $7.76(5.95-9.95)$ \\
\hline $35-44$ & $2320(3.2)$ & $1768768(20.1)$ & $1.31(1.26-1.37)$ & $71(8.6)$ & $8782(25.6)$ & $8.08(6.31-10.2)$ \\
\hline $45-54$ & $3839(5.3)$ & $1292297(14.7)$ & $2.97(2.88-3.07)$ & $79(9.5)$ & $5751(16.7)$ & $13.74(10.88-17.12)$ \\
\hline 55-64 & $8210(11.4)$ & $954048(10.8)$ & $8.61(8.42-8.79)$ & $115(13.9)$ & 3969 (11.6) & $28.97(23.92-34.78)$ \\
\hline 65-74 & $16888(23.4)$ & $794052(9.0)$ & $21.27(20.95-21.59)$ & $208(25.1)$ & $3357(9.8)$ & $61.96(53.83-70.98)$ \\
\hline $75-84$ & $21607(30.0)$ & $408679(4.6)$ & $52.87(52.17-53.58)$ & $195(23.5)$ & $1669(4.9)$ & $116.84(101.01-134.44)$ \\
\hline$\geq 85$ & $17207(23.9)$ & $137716(1.6)$ & $124.95(123.09-126.83)$ & $87(10.5)$ & $579(1.7)$ & $150.26(120.35-185.34)$ \\
\hline \multicolumn{7}{|l|}{ Sex } \\
\hline Female & $34663(48.1)$ & $4495701(51.1)$ & $7.71(7.63-7.79)$ & $461(55.5)$ & $16548(48.2)$ & $27.86(25.37-30.52)$ \\
\hline Male & $37405(51.9)$ & $4297777(48.9)$ & $8.70(8.62-8.79)$ & $369(44.5)$ & $17790(51.8)$ & $20.74(18.68-22.97)$ \\
\hline \multicolumn{7}{|c|}{ Neighbourhood income quintile } \\
\hline Q1 (lowest) & $16530(22.9)$ & $1820592(20.7)$ & $9.08(8.94-9.22)$ & $187(22.5)$ & $10487(30.5)$ & $17.83(15.37-20.58)$ \\
\hline Q2 & $13983(19.4)$ & $1701129(19.3)$ & $8.22(8.08-8.36)$ & $158(19.0)$ & $6884(20.0)$ & $22.95(19.51-26.82)$ \\
\hline Q3 & $12399(17.2)$ & $1664712(18.9)$ & $7.45(7.32-7.58)$ & $139(16.7)$ & $5672(16.5)$ & $24.51(20.60-28.94)$ \\
\hline Q4 & $11621(16.1)$ & $1675344(19.1)$ & $6.94(6.81-7.06)$ & $108(13.0)$ & $4670(13.6)$ & $23.13(18.97-27.92)$ \\
\hline Q5 (highest) & $11840(16.4)$ & $1654467(18.8)$ & $7.16(7.03-7.29)$ & $118(14.2)$ & $4380(12.8)$ & $26.94(22.30-32.26)$ \\
\hline Unknown & $5695(7.9)$ & $277234(3.2)$ & $20.54(20.01-21.08)$ & $120(14.5)$ & $2245(6.5)$ & $53.45(44.32-63.92)$ \\
\hline \multicolumn{7}{|l|}{ Dwelling } \\
\hline Urban & $59822(83.0)$ & $7322674(83.3)$ & $8.17(8.10-8.24)$ & $714(86.0)$ & $30443(88.7)$ & $23.45(21.76-25.24)$ \\
\hline Rural & $11727(16.3)$ & $1411045(16.0)$ & $8.31(8.16-8.46)$ & $110(13.3)$ & $3617(10.5)$ & $30.41(24.99-36.65)$ \\
\hline Unknown & $519(0.7)$ & $59759(0.7)$ & $8.68(7.95-9.47)$ & $6(0.7)$ & $278(0.8)$ & $21.58(7.92-46.98)$ \\
\hline \multicolumn{7}{|c|}{ Cause of death ${ }^{\star} \dagger$} \\
\hline Circulatory & $28902(40.1)$ & $8793478(100)$ & $3.29(3.25-3.32)$ & $238(28.7)$ & $34338(100)$ & $6.93(6.08-7.87)$ \\
\hline Neoplasm & $20494(28.4)$ & $8793478(100)$ & $2.33(2.30-2.36)$ & $145(17.5)$ & $34338(100)$ & $4.22(3.56-4.97)$ \\
\hline Metabolic $\ddagger$ & $5090(7.1)$ & $8793478(100)$ & $0.58(0.56-0.59)$ & $68(8.2)$ & $34338(100)$ & $1.98(1.54-2.51)$ \\
\hline Respiratory & $6153(8.5)$ & $8793478(100)$ & $0.70(0.68-0.72)$ & $98(11.8)$ & $34338(100)$ & $2.85(2.32-3.48)$ \\
\hline Accidental§ & $2815(3.9)$ & $8793478(100)$ & $0.32(0.31-0.33)$ & $49(5.9)$ & 34338 (100) & $1.43(1.06-1.89)$ \\
\hline Suicide & $1012(1.4)$ & $8793478(100)$ & $0.12(0.11-0.12)$ & $100(12)$ & $34338(100)$ & $2.91(2.37-3.54)$ \\
\hline
\end{tabular}

Note: $\mathrm{Cl}=$ confidence interval.

*For a classification of International Classification of Diseases, 9th Revision codes into cause-of-death categories, see Appendix 1 (available at www.cmaj.ca/lookup/suppl/doi:10.1503/ cmaj.161351/-/DC1).

†Proportions for causes of death do not sum to $100 \%$ because some data were suppressed, as a result of small cell sizes.

$\ddagger$ Metabolic causes of death included metabolic, nutritional, immunity and endocrine conditions, as well as diseases of the digestive system.

$\S$ Accidental causes of death included motor vehicle crashes, accidental poisoning, falls, fire, and drugs or adverse events in therapeutic use. 


\section{Results}

\section{Sample characteristics}

A total of 1639154 deaths were recorded in Ontario from Jan. 1, 1993, to Dec. 31, 2012. After exclusion of 16944 individuals aged 0 to 14 years and 959 individuals for whom cause of death was not available, there were 1621251 deaths in this time frame, of which 31349 (1.9\%) were deaths in individuals with schizophrenia. At both the earliest (Table 1) and latest (Table 2) time points, individuals who died with schizophrenia were often younger, female and resided in lower-income neighbourhoods. Those with schizophrenia were also more likely to die from each of the natural and unnatural causes of death than those who died without schizophrenia.

\section{Mortality time trends}

A nonsignificant interaction ( $p$ for interaction $=0.9$ ) between year of death and schizophrenia status in an age- and sexadjusted negative binomial model indicated that mortality time trends did not differ between those with and without

Table 2: Sociodemographic and clinical characteristics of individuals with and without schizophrenia who died in 2012

\begin{tabular}{|c|c|c|c|c|c|c|}
\hline \multirow[b]{2}{*}{ Characteristic } & \multicolumn{3}{|c|}{ Individuals without schizophrenia } & \multicolumn{3}{|c|}{ Individuals with schizophrenia } \\
\hline & $\begin{array}{l}\text { No. }(\%) \text { of } \\
\text { deaths }\end{array}$ & $\begin{array}{c}\text { Population 15-105 } \\
\text { yr, no. (\%) }\end{array}$ & $\begin{array}{l}\text { Crude rate per } 1000 \\
\qquad(95 \% \mathrm{Cl})\end{array}$ & $\begin{array}{l}\text { No. }(\%) \text { of } \\
\text { deaths }\end{array}$ & $\begin{array}{c}\text { Population 15-105 } \\
\text { yr, no. (\%) }\end{array}$ & $\begin{array}{l}\text { Crude rate per } 1000 \\
\qquad(95 \% \mathrm{Cl})\end{array}$ \\
\hline Overall & $86751(100)$ & $11750416(100)$ & $7.38(7.33-7.43)$ & $2074(100)$ & $111695(100)$ & $18.57(17.78-19.39)$ \\
\hline \multicolumn{7}{|l|}{ Age group, yr } \\
\hline $15-24$ & $636(0.7)$ & 1808089 (15.4) & $0.35(0.32-0.38)$ & $17(0.8)$ & $6215(5.6)$ & $2.74(1.59-4.38)$ \\
\hline $25-34$ & $796(0.9)$ & 1852851 (15.8) & $0.43(0.40-0.46)$ & $69(3.3)$ & $17051(15.3)$ & $4.05(3.15-5.12)$ \\
\hline 35-44 & $1563(1.8)$ & 1970832 (16.8) & $0.79(0.75-0.83)$ & $104(5.0)$ & 20399 (18.3) & $5.10(4.17-6.18)$ \\
\hline $45-54$ & 4619 (5.3) & 2203331 (18.8) & $2.10(2.04-2.16)$ & $271(13.1)$ & 27255 (24.4) & $9.94(8.79-11.2)$ \\
\hline $55-64$ & $9345(10.8)$ & 1752481 (14.9) & $5.33(5.22-5.44)$ & $398(19.2)$ & 21501 (19.2) & $18.51(16.74-20.42)$ \\
\hline $65-74$ & $14212(16.4)$ & $1138500(9.7)$ & $12.48(12.28-12.69)$ & $433(20.9)$ & $11311(10.1)$ & $38.28(34.76-42.06)$ \\
\hline 75-84 & $24179(27.9)$ & $681293(5.8)$ & $35.49(35.04-35.94)$ & $433(20.9)$ & $5490(4.9)$ & $78.87(71.62-86.66)$ \\
\hline$\geq 85$ & $31401(36.2)$ & 343039 (2.9) & 91.54 (90.53-92.56) & $349(16.8)$ & $2473(2.2)$ & $141.12(126.7-156.73)$ \\
\hline \multicolumn{7}{|l|}{ Sex } \\
\hline Female & $43100(49.7)$ & $6002623(51.1)$ & $7.18(7.11-7.25)$ & $1090(52.6)$ & $49945(44.7)$ & $21.82(20.55-23.16)$ \\
\hline Male & $43651(50.3)$ & $5747793(48.9)$ & $7.59(7.52-7.67)$ & $984(47.4)$ & $61750(55.3)$ & $15.94(14.95-16.96)$ \\
\hline \multicolumn{7}{|c|}{ Neighbourhood income quintile } \\
\hline Q1 (lowest) & $19655(22.7)$ & $2245174(19.1)$ & $8.75(8.63-8.88)$ & $706(34.0)$ & $38091(34.1)$ & $18.53(17.19-19.95)$ \\
\hline Q2 & $17789(20.5)$ & $2308559(19.6)$ & $7.71(7.59-7.82)$ & $392(18.9)$ & $24232(21.7)$ & $16.18(14.61-17.86)$ \\
\hline Q3 & $16811(19.4)$ & 2330823 (19.8) & $7.21(7.10-7.32)$ & $365(17.6)$ & $18537(16.6)$ & $19.69(17.72-21.82)$ \\
\hline Q4 & $16353(18.9)$ & $2445142(20.8)$ & 6.69 (6.59-6.79) & $309(14.9)$ & $16466(14.7)$ & $18.77(16.73-20.98)$ \\
\hline Q5 (highest) & 15704 (18.1) & $2371682(20.2)$ & $6.62(6.52-6.73)$ & $277(13.4)$ & $13490(12.1)$ & $20.53(18.19-23.10)$ \\
\hline Unknown & $439(0.5)$ & $49036(0.4)$ & $8.95(8.13-9.83)$ & $25(1.2)$ & $879(0.8)$ & 28.44 (18.41-41.99) \\
\hline \multicolumn{7}{|l|}{ Dwelling } \\
\hline Urban & 73862 (85.1) & $10422041(88.7)$ & $7.09(7.04-7.14)$ & $1863(89.8)$ & 102191 (91.5) & $18.23(17.41-19.08)$ \\
\hline Rural & $12855(14.8)$ & $1323106(11.3)$ & $9.72(9.55-9.89)$ & $208(10.0)$ & $9439(8.5)$ & $22.04(19.14-25.24)$ \\
\hline Unknown & $34(<0.1)$ & $5269(<0.1)$ & $6.45(4.47-9.02)$ & $\leq 5$ & $65(0.1)$ & $46.15(9.52-134.88)$ \\
\hline \multicolumn{7}{|c|}{ Cause of death ${ }^{\star} \dagger$} \\
\hline Circulatory & $23958(27.6)$ & $11750416(100)$ & $2.04(2.01-2.06)$ & $521(25.1)$ & $111695(100)$ & $4.66(4.27-5.08)$ \\
\hline Neoplasm & $27254(31.4)$ & $11750416(100)$ & $2.32(2.29-2.35)$ & 396 (19.1) & $111695(100)$ & $3.55(3.20-3.91)$ \\
\hline Metabolic & $7326(8.4)$ & $11750416(100)$ & $0.62(0.61-0.64)$ & $194(9.4)$ & $111695(100)$ & $1.74(1.50-2.00)$ \\
\hline Respiratory & $7505(8.7)$ & $11750416(100)$ & $0.64(0.62-0.65)$ & $207(10.0)$ & $111695(100)$ & $1.85(1.61-2.12)$ \\
\hline Accidental§ & $4217(4.9)$ & $11750416(100)$ & $0.36(0.35-0.37)$ & $144(6.9)$ & $111695(100)$ & $1.29(1.09-1.52)$ \\
\hline Suicide & $1078(1.2)$ & $11750416(100)$ & $0.09(0.09-0.10)$ & $98(4.7)$ & $111695(100)$ & $0.88(0.71-1.07)$ \\
\hline
\end{tabular}




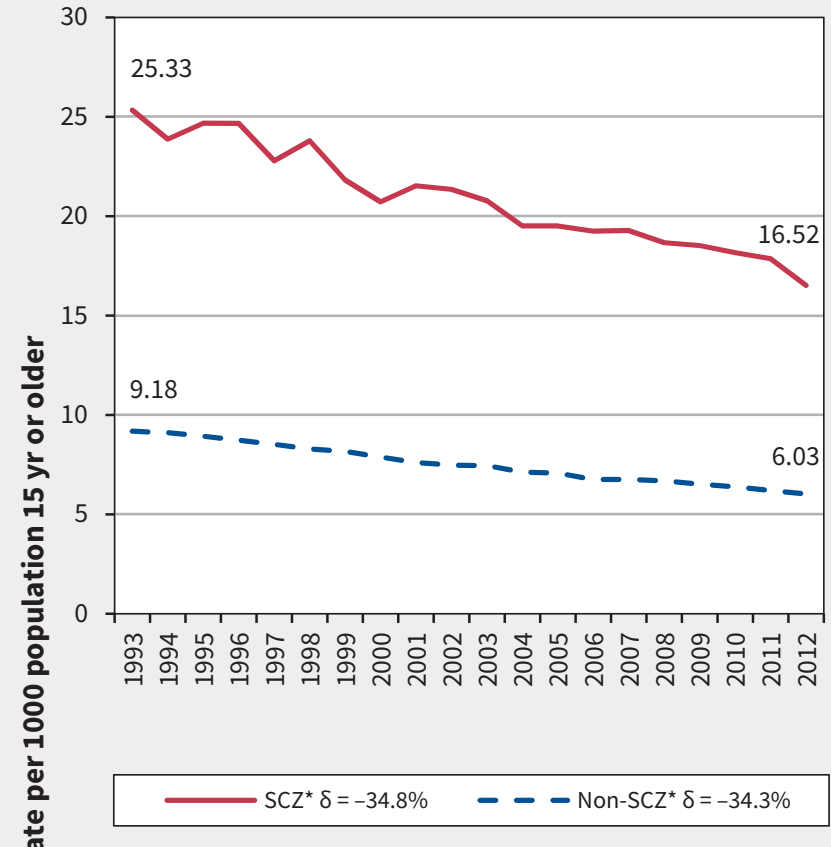

By neighbourhood income quintile

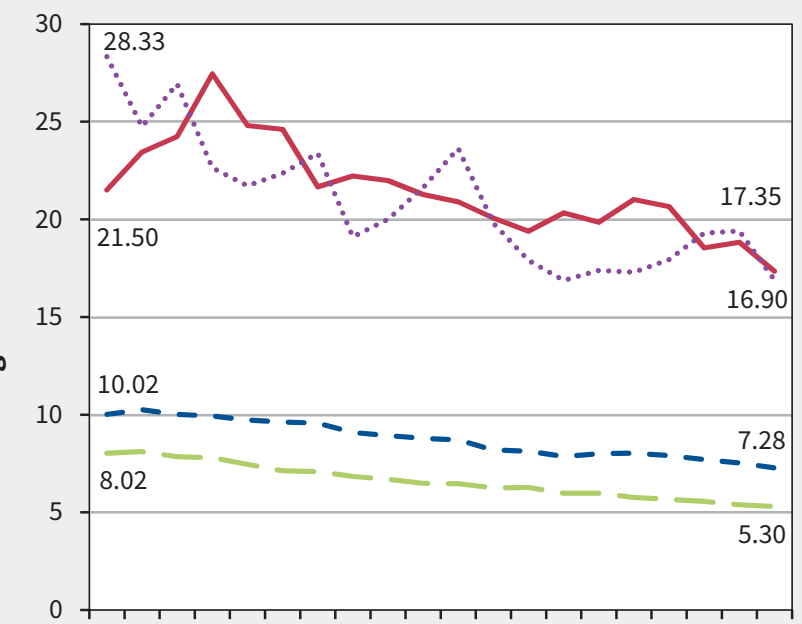

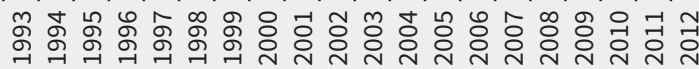

Year

\begin{tabular}{|c|c|}
\hline $\begin{aligned} & \text { SCZ Q1 } \delta=-19.3 \% \\
\cdots & \text { SCZ Q }{ }^{\star} \delta=-40.3 \%\end{aligned}$ & $\begin{array}{l}=- \text { Non-SCZ Q1* } \delta=-27.3 \% \\
=- \text { Non-SCZ Q5 }^{\star} \delta=-33.9 \%\end{array}$ \\
\hline
\end{tabular}

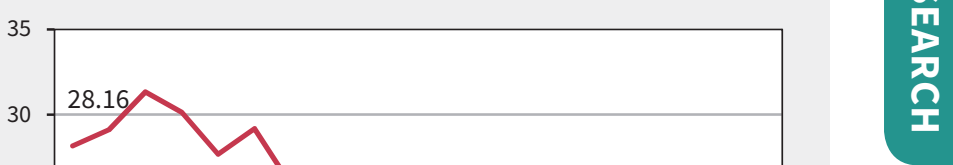

SCZ males ${ }^{\star} \delta=-33.3 \% \quad$ - - - Non-SCZ males ${ }^{\star} \delta=-37.7 \%$ .... SCZ females ${ }^{\star} \delta=-36.6 \%=-$ Non-SCZ females ${ }^{\star} \delta=-30.3 \%$

By urban/rural residence

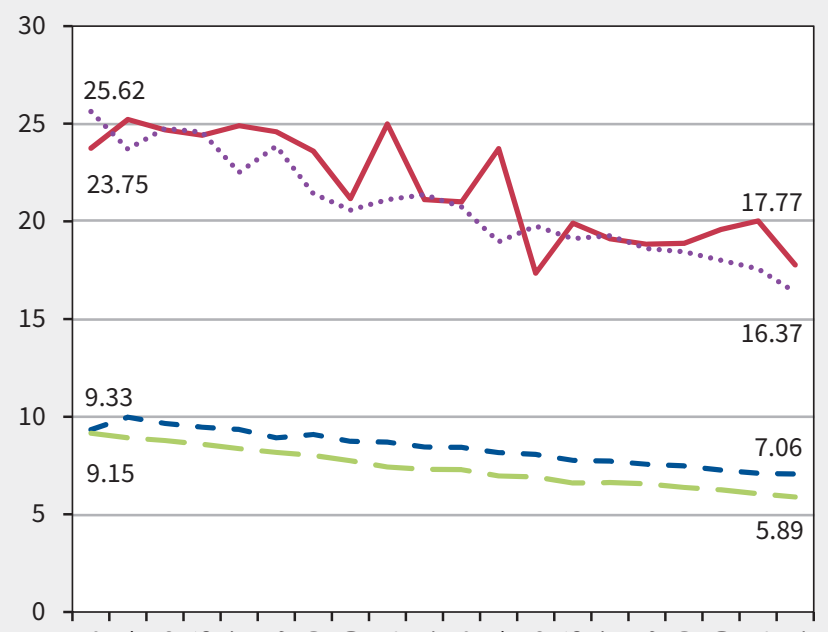

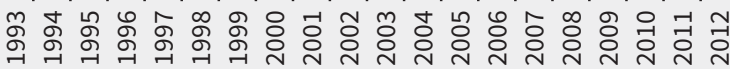

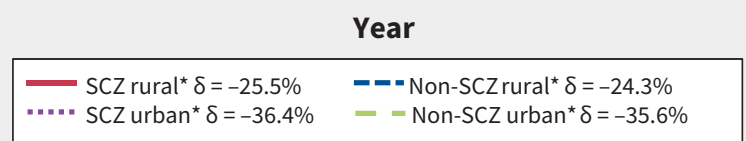

Figure 1: Temporal trends in all-cause age- and sex-standardized mortality rates in individuals with and without schizophrenia (SCZ) overall, by sex, by income quintile (where Q1 = lowest and Q5 = highest) and by rural or urban residence. Trends were examined using unadjusted linear regression models, and significant $(p<0.05)$ trends between 1993 and 2012 are indicated by an asterisk. Delta $(\delta)$ values indicate the relative differences between 1993 and 2012 rates, expressed as a percentage of the 1993 rate; for absolute differences, see Appendix 2, available at www.cmaj.ca/lookup/suppl/ doi:10.1503/cmaj. 161351/-/DC1). Mortality rates were age- and sex-standardized to the 2006 Ontario population using the direct method. For each trend line, the 1993 and 2012 data points are noted explicitly within the graph. 
schizophrenia. Individuals with schizophrenia experienced an absolute decline in all-cause ASMR of 8.81 deaths per 1000 (from 25.33 to 16.52 ) between 1993 and 2012, corresponding to a significant relative decline of $34.8 \%$ ( $p$ for trend $<0.001$ ). Those without schizophrenia experienced an absolute ASMR reduction of 3.15 deaths per 1000 (from 9.18 to 6.03), which represented a significant decline of $34.3 \%(p<0.001)$ (see Figure 1 and Appendix 2 [available at www.cmaj.ca/lookup/suppl/doi:10.1503/ cmaj.161351/-/DC1] for details). Although the relative declines were observed in parallel, the absolute difference in ASMRs between the groups decreased from 16.15 to 10.49 deaths per 1000 over the study period $(p<0.001)$.

Similarly, according to the fully adjusted negative binomial model, mortality time trends did not differ between the groups
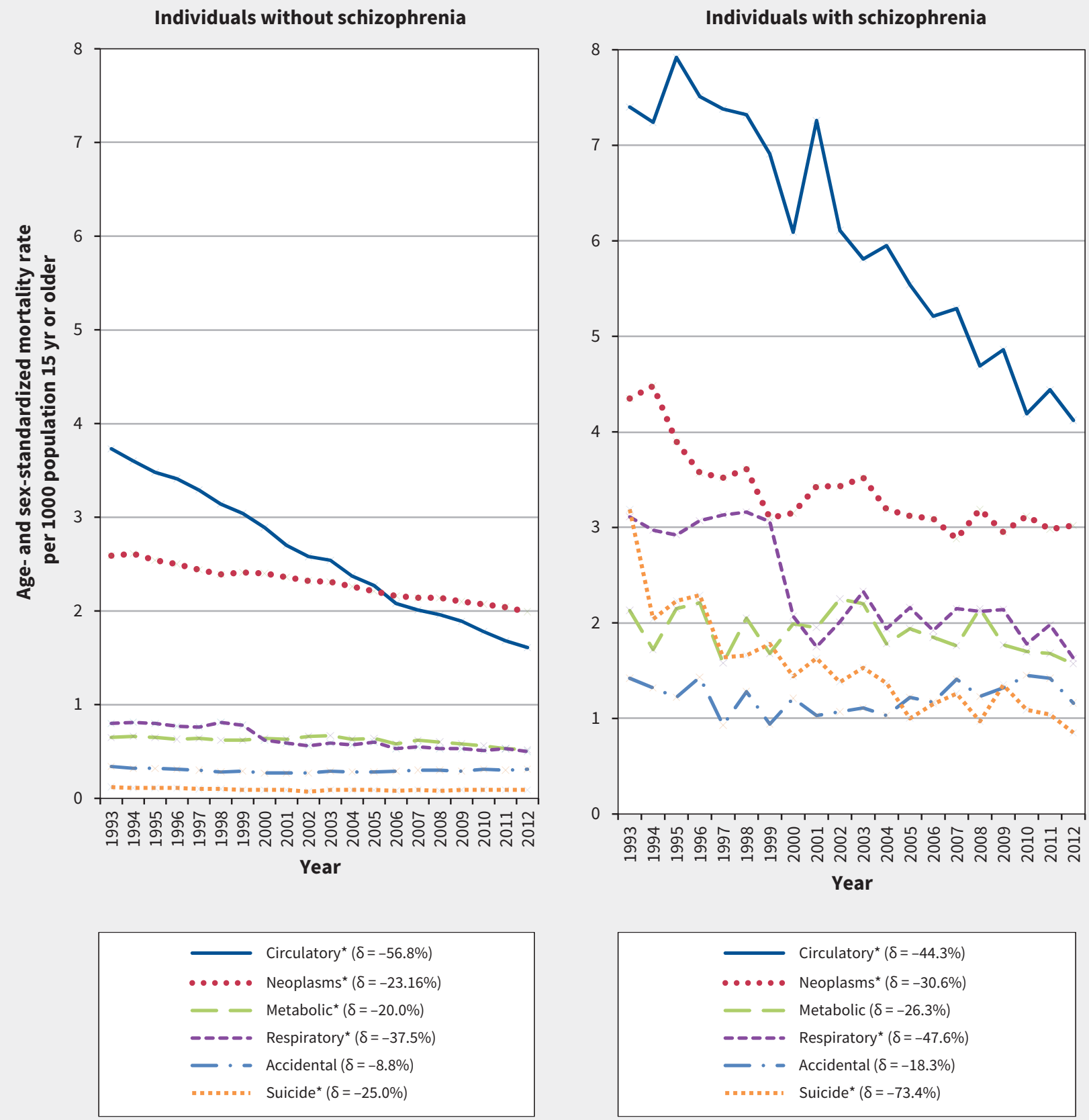

Figure 2: Temporal trends in cause-specific (natural and unnatural) age- and sex-standardized mortality rates in individuals with and without schizophrenia. Trends were examined using unadjusted linear regression models, and significant $(p<0.05)$ trends between 1993 and 2012 are indicated by an asterisk. Delta $(\delta)$ values indicate the relative differences between 1993 and 2012 rates, expressed as a percentage of the 1993 rate; for annual rates and absolute differences, see Tables 3 and 4. Accidental causes of death include motor vehicle crashes, inadvertent poisoning, falls, fire, and drugs or adverse events in therapeutic use. Metabolic causes include metabolic, nutritional, immunity and endocrine conditions, as well as diseases of the digestive system. Mortality rates were age-and sex-standardized to the 2006 Ontario population using the direct method. 
( $p=0.8$; interaction was removed). Individuals with schizophrenia were 3.12 times more likely than those without schizophrenia to die from any cause (MRR 3.12, 95\% Cl 3.06-3.17), with adjustment for age, sex, income quintile, rurality and year of death. The average annual decline in mortality rates for both groups was $2 \%$ (MRR 0.98, 95\% Cl 0.98-0.98). Mortality time trends did not differ by sex ( $p$ for interaction $=0.6$ ), by income quintile $(p=0.8)$ or by rurality $(p=0.4)$, but in both groups, males and individuals from lower-income neighbourhoods and rural areas had higher ASMRs.

Although cause-specific ASMRs were greater among individuals with schizophrenia in absolute terms, tests for interactions in age- and sex-adjusted negative binomial models showed that mortality time trends did not differ between the groups for most conditions, with the exception of circulatory deaths ( $p=$ $0.003)$, accidents $(p=0.002)$ and suicides $(p<0.001)$, whereby those with schizophrenia experienced greater relative declines than the general population for unnatural causes of death but a lesser relative decline in cardiovascular mortality (Figure 2, Table 3 and Table 4). Equivalent findings were observed using fully adjusted negative binomial models. Up to 2005, the highest ASMR for those without schizophrenia was for circulatory causes (with a relative decline of 57\% between 1993 and 2012), but after 2005, neoplasms became the leading cause of death in this population (1.99 per 1000). By contrast, circulatory mortality remained the leading cause of death for those with schizophrenia throughout the years, with a $44 \%$ relative decline over-

Table 3: Temporal trends and comparison of ASMRs for deaths related to circulatory, neoplasm and metabolic causes in individuals with and without schizophrenia (1993-2012)

\begin{tabular}{|c|c|c|c|c|c|c|c|c|c|c|c|c|}
\hline \multirow[b]{3}{*}{ Year } & \multicolumn{12}{|c|}{ Cause of death; ASMR per 1000 population aged 15 yr or older* } \\
\hline & \multicolumn{4}{|c|}{ Circulatory } & \multicolumn{4}{|c|}{ Neoplasms } & \multicolumn{4}{|c|}{ Metabolic } \\
\hline & $\begin{array}{l}\text { Non- } \\
\text { SCZ }\end{array}$ & SCZ & RR† & RD $\ddagger$ & $\begin{array}{l}\text { Non- } \\
\text { SCZ }\end{array}$ & SCZ & RR† & RD $\ddagger$ & $\begin{array}{l}\text { Non- } \\
\text { SCZ }\end{array}$ & SCZ & RR† & RD $\ddagger$ \\
\hline 1993 & 3.73 & 7.40 & 1.98 & 3.67 & 2.59 & 4.35 & 1.68 & 1.76 & 0.65 & 2.13 & 3.28 & 1.48 \\
\hline 1994 & 3.60 & 7.24 & 2.01 & 3.64 & 2.61 & 4.48 & 1.72 & 1.87 & 0.66 & 1.72 & 2.61 & 1.06 \\
\hline 1995 & 3.48 & 7.92 & 2.28 & 4.44 & 2.54 & 3.90 & 1.54 & 1.36 & 0.65 & 2.15 & 3.31 & 1.50 \\
\hline 1996 & 3.41 & 7.51 & 2.20 & 4.10 & 2.50 & 3.57 & 1.43 & 1.07 & 0.63 & 2.21 & 3.51 & 1.58 \\
\hline 1997 & 3.29 & 7.38 & 2.24 & 4.09 & 2.44 & 3.52 & 1.44 & 1.08 & 0.64 & 1.58 & 2.47 & 0.94 \\
\hline 1998 & 3.14 & 7.32 & 2.33 & 4.18 & 2.39 & 3.61 & 1.51 & 1.22 & 0.62 & 2.05 & 3.31 & 1.43 \\
\hline 1999 & 3.04 & 6.91 & 2.27 & 3.87 & 2.41 & 3.10 & 1.29 & 0.69 & 0.62 & 1.68 & 2.71 & 1.06 \\
\hline 2000 & 2.89 & 6.09 & 2.11 & 3.20 & 2.40 & 3.15 & 1.31 & 0.75 & 0.64 & 1.99 & 3.11 & 1.35 \\
\hline 2001 & 2.70 & 7.26 & 2.69 & 4.56 & 2.36 & 3.43 & 1.45 & 1.07 & 0.63 & 1.95 & 3.10 & 1.32 \\
\hline 2002 & 2.58 & 6.11 & 2.37 & 3.53 & 2.32 & 3.43 & 1.48 & 1.11 & 0.66 & 2.25 & 3.41 & 1.59 \\
\hline 2003 & 2.54 & 5.81 & 2.29 & 3.27 & 2.31 & 3.52 & 1.52 & 1.21 & 0.67 & 2.20 & 3.28 & 1.53 \\
\hline 2004 & 2.37 & 5.95 & 2.51 & 3.58 & 2.26 & 3.19 & 1.41 & 0.93 & 0.63 & 1.78 & 2.83 & 1.15 \\
\hline 2005 & 2.27 & 5.54 & 2.44 & 3.27 & 2.21 & 3.12 & 1.41 & 0.91 & 0.64 & 1.94 & 3.03 & 1.30 \\
\hline 2006 & 2.08 & 5.21 & 2.50 & 3.13 & 2.16 & 3.09 & 1.43 & 0.93 & 0.58 & 1.85 & 3.19 & 1.27 \\
\hline 2007 & 2.01 & 5.29 & 2.63 & 3.28 & 2.14 & 2.88 & 1.35 & 0.74 & 0.62 & 1.76 & 2.84 & 1.14 \\
\hline 2008 & 1.96 & 4.69 & 2.39 & 2.73 & 2.14 & 3.19 & 1.49 & 1.05 & 0.60 & 2.15 & 3.58 & 1.55 \\
\hline 2009 & 1.89 & 4.86 & 2.57 & 2.97 & 2.10 & 2.95 & 1.40 & 0.85 & 0.58 & 1.77 & 3.05 & 1.19 \\
\hline 2010 & 1.78 & 4.19 & 2.35 & 2.41 & 2.07 & 3.12 & 1.51 & 1.05 & 0.56 & 1.70 & 3.04 & 1.14 \\
\hline 2011 & 1.68 & 4.44 & 2.64 & 2.76 & 2.04 & 2.98 & 1.46 & 0.94 & 0.53 & 1.68 & 3.17 & 1.15 \\
\hline 2012 & 1.61 & 4.12 & 2.56 & 2.51 & 1.99 & 3.02 & 1.52 & 1.03 & 0.52 & 1.57 & 3.02 & 1.05 \\
\hline Average over time & & & NA & NA & & & 1.47 & NA & & & 3.09 & 1.29 \\
\hline Absolute difference§ & 2.12 & 3.28 & & & 0.60 & 1.33 & & & 0.13 & 0.56 & & \\
\hline Relative difference & $-56.8 \%$ & $-44.3 \%$ & & & $-23.2 \%$ & $-30.6 \%$ & & & $-20.0 \%$ & $-26.3 \%$ & & \\
\hline$p$ for trend ${ }^{\star \star}$ & $<0.001$ & $<0.001$ & & & $<0.001$ & $<0.001$ & & & $<0.001$ & 0.09 & & \\
\hline 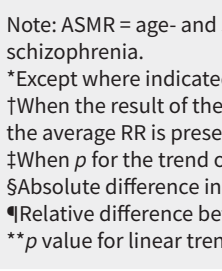 & $\begin{array}{l}\text { tandardized } \\
\text { erwise. } \\
\text { for interacti } \\
\text { in the row } \mathrm{f} \\
\text { over time w } \\
\text { Rs per } 1000 \\
\text { n } 1993 \text { and } \\
\text { tained using }\end{array}$ & $\begin{array}{l}\text { mortality } r \\
\text { n between } \\
r \text { "average } \\
\text { s greater } t \\
\text { etween } 19 \\
012 \text { rates, } € \\
\text { unadjustec }\end{array}$ & $\begin{array}{l}\mathrm{NA}=\mathrm{no} \\
\text { r of dea } \\
\mathrm{r} \text { time." } \\
0.05 \text {, th } \\
\text { and } 2012 \\
\text { essed a } \\
\text { ear regr }\end{array}$ & $\begin{array}{l}\text { icable, } 1 \\
\text { age RDizo } \\
\text { centage }\end{array}$ & $\begin{array}{l}-S C Z=\text { ind } \\
\text { enia status } \\
\text { resented ir } \\
\text { the } 1993 \mathrm{r}\end{array}$ & $\begin{array}{l}\text { duals with } \\
\text { ge-and se } \\
\text { he row for }\end{array}$ & $\begin{array}{l}\text { chizoph } \\
\text { usted ne } \\
\text { age ove }\end{array}$ & $\begin{array}{l}\mathrm{RD}=\mathrm{rat} \\
\text { binom } \\
\text { " }\end{array}$ & $\begin{array}{l}\text { lifference, } \\
\text { model) wa }\end{array}$ & $\begin{array}{l}\text { = rate ratic } \\
\text { ot statistic }\end{array}$ & $\begin{array}{l}Z=\text { indi } \\
\text { signific }\end{array}$ & $\begin{array}{l}\text { Is with } \\
>0.05 \text { ), }\end{array}$ \\
\hline
\end{tabular}


all (from 7.40 to 4.12 per 1000). The absolute differences between the groups for metabolic ASMRs averaged 1.29 per 1000. Relative reductions in suicide-related mortality rates were greatest for those with schizophrenia, whereby in 2012, the ASMR due to accidental causes surpassed the ASMR due to suicide in this group (1.16 v. 0.85 per 1000).

The sensitivity analysis, in which the prevalence of schizophrenia in 2012 was applied to all annual estimates throughout the study period, revealed that the relative between-group difference in crude all-cause mortality rates increased from 2.50 to 2.52 per 1000 , whereas the absolute difference declined from 12.28 to 11.19 per 1000 (see Appendix 3, available at www.cmaj. ca/lookup/suppl/doi:10.1503/cmaj.161351/-/DC1)

\section{Premature mortality}

On average, individuals with schizophrenia died 8 years younger than those without (Table 5). The mean age at death for those without schizophrenia increased from 73.3 to 76.7 years between 1993 and 2012. From 2001 onward, these individuals no longer met the standard definition for premature mortality. ${ }^{23}$ By contrast, premature mortality for those with schizophrenia persisted over the years, with the average age at death increasing from 64.7 to 67.4. Time trends in age- and sex-standardized rates of YPLL mirrored those of the ASMRs, whereby decreases were observed in parallel. Those with schizophrenia lost more potential years of life than those without schizophrenia, overall and for each cause of death (Appendix 4, available at www. cmaj.ca/lookup/suppl/doi:10.1503/cmaj.161351/-/DC1). Throughout

Table 4: Temporal trends and comparisons of ASMRs for deaths related to respiratory causes, accidents and suicide in individuals with and without schizophrenia (1993-2012)

\begin{tabular}{|c|c|c|c|c|c|c|c|c|c|c|c|c|}
\hline \multirow[b]{3}{*}{ Year } & \multicolumn{12}{|c|}{ Cause of death; ASMR, per 1000 population aged 15 yr or older* } \\
\hline & \multicolumn{4}{|c|}{ Respiratory } & \multicolumn{4}{|c|}{ Accidents } & \multicolumn{4}{|c|}{ Suicide } \\
\hline & $\begin{array}{l}\text { Non- } \\
\text { SCZ }\end{array}$ & SCZ & RR† & RD $\ddagger$ & $\begin{array}{l}\text { Non- } \\
\text { SCZ }\end{array}$ & SCZ & RR† & RD $\ddagger$ & $\begin{array}{l}\text { Non- } \\
\text { SCZ }\end{array}$ & SCZ & RRT & RD $\ddagger$ \\
\hline 1993 & 0.80 & 3.11 & 3.89 & 2.31 & 0.34 & 1.42 & 4.18 & 1.08 & 0.12 & 3.19 & 26.58 & 3.07 \\
\hline 1994 & 0.81 & 2.97 & 3.67 & 2.16 & 0.32 & 1.32 & 4.13 & 1.00 & 0.11 & 2.04 & 18.55 & 1.93 \\
\hline 1995 & 0.80 & 2.92 & 3.65 & 2.12 & 0.32 & 1.22 & 3.81 & 0.90 & 0.11 & 2.23 & 20.27 & 2.12 \\
\hline 1996 & 0.77 & 3.07 & 3.99 & 2.30 & 0.31 & 1.43 & 4.61 & 1.12 & 0.11 & 2.29 & 20.82 & 2.18 \\
\hline 1997 & 0.76 & 3.13 & 4.12 & 2.37 & 0.30 & 0.93 & 3.10 & 0.63 & 0.10 & 1.64 & 16.40 & 1.54 \\
\hline 1998 & 0.81 & 3.16 & 3.90 & 2.35 & 0.28 & 1.28 & 4.57 & 1.00 & 0.10 & 1.66 & 16.60 & 1.56 \\
\hline 1999 & 0.78 & 3.06 & 3.92 & 2.28 & 0.29 & 0.94 & 3.24 & 0.65 & 0.09 & 1.78 & 19.78 & 1.69 \\
\hline 2000 & 0.62 & 2.07 & 3.34 & 1.45 & 0.27 & 1.21 & 4.48 & 0.94 & 0.09 & 1.44 & 16.00 & 1.35 \\
\hline 2001 & 0.59 & 1.75 & 2.97 & 1.16 & 0.27 & 1.03 & 3.81 & 0.76 & 0.09 & 1.63 & 18.11 & 1.54 \\
\hline 2002 & 0.56 & 2.01 & 3.59 & 1.45 & 0.27 & 1.07 & 3.96 & 0.80 & 0.07 & 1.38 & 19.71 & 1.31 \\
\hline 2003 & 0.59 & 2.33 & 3.95 & 1.74 & 0.29 & 1.11 & 3.83 & 0.82 & 0.09 & 1.53 & 17.00 & 1.44 \\
\hline 2004 & 0.57 & 1.94 & 3.40 & 1.37 & 0.28 & 1.03 & 3.68 & 0.75 & 0.09 & 1.37 & 15.22 & 1.28 \\
\hline 2005 & 0.60 & 2.16 & 3.60 & 1.56 & 0.28 & 1.22 & 4.36 & 0.94 & 0.09 & 1.00 & 11.11 & 0.91 \\
\hline 2006 & 0.53 & 1.92 & 3.62 & 1.39 & 0.29 & 1.17 & 4.03 & 0.88 & 0.08 & 1.15 & 14.38 & 1.07 \\
\hline 2007 & 0.55 & 2.15 & 3.91 & 1.60 & 0.30 & 1.41 & 4.70 & 1.11 & 0.09 & 1.26 & 14.00 & 1.17 \\
\hline 2008 & 0.53 & 2.12 & 4.00 & 1.59 & 0.30 & 1.23 & 4.10 & 0.93 & 0.08 & 0.97 & 12.13 & 0.89 \\
\hline 2009 & 0.53 & 2.14 & 4.04 & 1.61 & 0.29 & 1.32 & 4.55 & 1.03 & 0.09 & 1.35 & 15.00 & 1.26 \\
\hline 2010 & 0.51 & 1.78 & 3.49 & 1.27 & 0.31 & 1.45 & 4.68 & 1.14 & 0.09 & 1.09 & 12.11 & 1.00 \\
\hline 2011 & 0.53 & 1.98 & 3.74 & 1.45 & 0.30 & 1.42 & 4.73 & 1.12 & 0.09 & 1.04 & 11.56 & 0.95 \\
\hline 2012 & 0.50 & 1.63 & 3.26 & 1.13 & 0.31 & 1.16 & 3.74 & 0.85 & 0.09 & 0.85 & 9.44 & 0.76 \\
\hline Average over time & & & 3.70 & NA & & & 4.12 & 0.92 & & & NA & NA \\
\hline Absolute difference§ & 0.3 & 1.48 & & & 0.03 & 0.26 & & & 0.03 & 2.34 & & \\
\hline Relative difference $₫$ & $-37.5 \%$ & $-47.6 \%$ & & & $-8.8 \%$ & $-18.3 \%$ & & & $-25.0 \%$ & $-73.4 \%$ & & \\
\hline$p$ for trend ${ }^{\star \star}$ & $<0.001$ & $<0.001$ & & & 0.3 & 0.6 & & & $<0.001$ & $<0.001$ & & \\
\hline \multicolumn{13}{|c|}{ 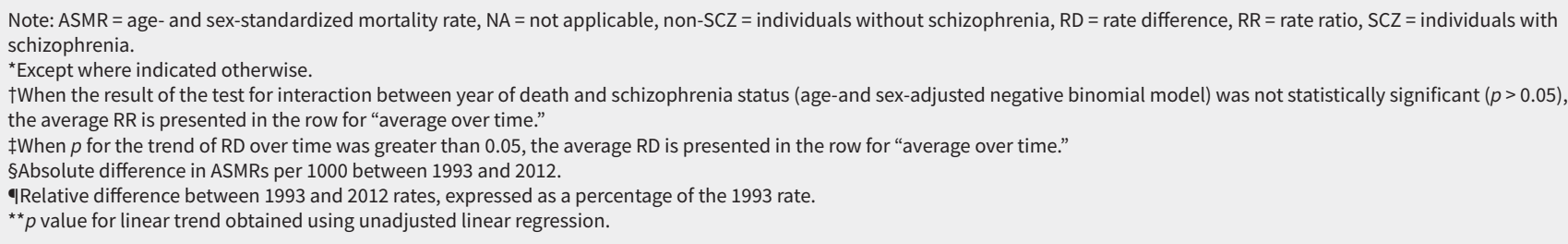 } \\
\hline
\end{tabular}


the study period, those without schizophrenia lost 43.9 potential years of life per 1000 persons, compared with 226.3 YPLL among those with schizophrenia.

\section{Interpretation}

Between 1993 and 2012, individuals with schizophrenia experienced 3 times greater mortality rates, compared with the general population, even after adjustment for sociodemographic factors. All-cause mortality rates in both groups declined in parallel by about 35\%, and were higher in men, those with low income and rural dwellers. Although the relative 3 -fold gap between the groups persisted, the absolute difference declined from 16.15 to 10.49 deaths per 1000. Cause-specific ASMRs were greater for those with schizophrenia, with circulatory disease accounting for most deaths. By contrast, neoplasm-related deaths became more common after 2005 among those without schizophrenia. Among those with schizophrenia, relative declines throughout the 20 years were greater for unnatural deaths but smaller for circulatory deaths. Those with schizophrenia also died younger and lost more potential years of life.
Previous studies involving individuals with schizophrenia showed widening mortality gaps relative to the general population, but were limited by small samples ${ }^{1,9}$ or by an older observation period, ${ }^{1,9,10}$ which may not reflect more recent mortality reductions in developed countries. ${ }^{2}$ The 3 -fold elevated mortality rates that we observed are consistent with the scientific literature, ${ }^{5}$ as is the finding that the relative gap did not close over the years. ${ }^{12,14}$ Even in Scandinavian countries, which provide highquality health care, the mortality gap remains wide and has decreased only modestly over the past 2 decades. ${ }^{12}$ Neoplasmrelated mortality surpassed circulatory mortality in the general population, concurrent with a longer life expectancy. ${ }^{25}$ By contrast, individuals with schizophrenia have not benefited from reductions in cardiovascular deaths to the same extent. ${ }^{26,27}$ These conditions, along with higher rates of suicide and accidental deaths, contribute to premature mortality. Although higher rates of unnatural deaths tend to occur more often in early adulthood, ${ }^{28}$ our analysis of YPLL reflects the premature mortality toll resulting from natural causes, suggesting that schizophrenia can indeed be considered a "life-shortening disease," as some authors assert. ${ }^{29}$

Table 5: Mean age at death and age- and sex-standardized YPLL due to all causes, per 1000 population aged 15-75 years

\begin{tabular}{|c|c|c|c|c|c|c|c|c|c|c|}
\hline Year & \multicolumn{5}{|c|}{ Individuals without schizophrenia } & \multicolumn{5}{|c|}{ Individuals with schizophrenia } \\
\hline 1993 & $73.3 \pm 15.4$ & 33254 & 473740 & 8247083 & 56.55 & $64.7 \pm 18.1$ & 548 & 10664 & 32090 & 308.30 \\
\hline 1994 & $73.7 \pm 15.2$ & 33399 & 466442 & 8366761 & 54.56 & $66.6 \pm 17.6$ & 587 & 10565 & 37073 & 263.73 \\
\hline 1997 & $74.5 \pm 14.9$ & 31982 & 438028 & 8693881 & 48.81 & $67.8 \pm 17.2$ & 717 & 12934 & 49037 & 238.87 \\
\hline 1998 & $74.8 \pm 14.8$ & 31466 & 432081 & 8827185 & 47.14 & $67.8 \pm 16.8$ & 783 & 13838 & 52966 & 253.51 \\
\hline 1999 & $74.8 \pm 14.8$ & 31628 & 440654 & 8977679 & 46.99 & $67.6 \pm 17.4$ & 797 & 14994 & 56536 & 234.39 \\
\hline 2000 & $75.0 \pm 14.8$ & 31065 & 440393 & 9158993 & 45.90 & $67.5 \pm 17.3$ & 829 & 15273 & 60092 & 220.73 \\
\hline 2004 & $75.3 \pm 14.9$ & 30716 & 446458 & 9841292 & 42.08 & $68.3 \pm 17.2$ & 923 & 16762 & 73290 & 212.23 \\
\hline 2005 & $75.7 \pm 14.9$ & 30634 & 442825 & 10000965 & 40.82 & $67.6 \pm 17.6$ & 995 & 19142 & 77288 & 219.52 \\
\hline 2006 & $75.7 \pm 15.0$ & 30235 & 447009 & 10159982 & 40.26 & $67.2 \pm 17.3$ & 1071 & 20410 & 81640 & 216.45 \\
\hline 2007 & $75.9 \pm 15.0$ & 30775 & 453703 & 10059439 & 40.92 & $67.7 \pm 17.0$ & 1110 & 20422 & 84971 & 211.98 \\
\hline 2008 & $76.2 \pm 14.8$ & 30679 & 444794 & 10101925 & 39.61 & $67.6 \pm 16.5$ & 1184 & 20866 & 88439 & 203.34 \\
\hline 2009 & $76.2 \pm 14.9$ & 30660 & 447309 & 10268501 & 38.95 & $67.2 \pm 17.1$ & 1209 & 22815 & 92430 & 216.67 \\
\hline 2010 & $76.4 \pm 15.0$ & 30820 & 452146 & 10424582 & 38.53 & $67.2 \pm 17.3$ & 1233 & 23419 & 96204 & 213.20 \\
\hline 2011 & $76.6 \pm 14.8$ & 30822 & 441451 & 10571515 & 36.82 & $67.4 \pm 17.2$ & 1247 & 23347 & 100086 & 208.79 \\
\hline 2012 & $76.7 \pm 15.0$ & 31171 & 445588 & 10726084 & 36.54 & $67.4 \pm 16.7$ & 1292 & 23156 & 103732 & 190.90 \\
\hline
\end{tabular}


Access to health care and lifestyle factors may explain the elevated mortality among individuals with schizophrenia, ${ }^{3}$ who have a higher rate of modifiable risk factors such as smoking, alcohol consumption, poor diet and lack of exercise, ${ }^{4,18}$ and an increased likelihood of being obese and developing diabetes mellitus, possibly related to weight gain associated with antipsychotic medication. ${ }^{3,30}$ The elevated mortality rate in this group may also be due to limited access to general health services, given that patients with severe mental illness are less likely to receive standard levels of care for physical diseases, as well as cardiovascular screening and prevention, than would be expected for a nonpsychiatric population..$^{3,18,31}$ Nonetheless, the reductions in absolute inequality between the groups signal that some public health efforts are likely having an effect.

\section{Limitations}

This repeated cross-sectional study was based on yearly prevalent cases of schizophrenia. Because these individuals may already have survived the period of greatest risk for suicide following first service contact, ${ }^{9}$ the mortality rates reported here may be underestimates. Furthermore, our algorithm relied on health service contact to ascertain individuals with schizophrenia. Over the 20 years of the study, the number of cases gradually increased because of stable incidence and a longer accrual period, which increased the overall prevalence of schizophrenia over time. This would lead to overestimation of schizophrenia-related mortality rates early in the observation period, because the denominator would be artificially low. Although a sensitivity analysis in which the prevalence of schizophrenia in 2012 was applied to all annual estimates revealed a minimal degree of ascertainment bias, it may be that the mortality gap between individuals with and without schizophrenia is not persisting; rather, it may be increasing. Additionally, information about health risk factors, such as smoking, substance abuse, body mass index and medication use, was unavailable. These factors are not needed for estimating ASMRs, but they may explain the observed trends. Lastly, administrative data may have missed individuals with undiagnosed or untreated illness, and those seeking care through community organizations or private specialists. However, given the severity and chronic nature of schizophrenia, it is likely that most patients would be admitted to hospital at least once and would thus have been included in this study.

\section{Conclusion}

Individuals with and without schizophrenia experienced similar relative declines in all-cause mortality over the study period, which resulted in a persistent 3-fold gap. While neoplasms have become more common in the general population, individuals with schizophrenia have lagged behind in terms of reductions to the mortality risk posed by cardiovascular disease. Although there have been numerous calls to action to help individuals with severe mental illness, such as schizophrenia, to manage chronic medical illnesses, ${ }^{18,26,29}$ and although the declining trends and narrowing absolute gap that we observed are positive developments, more effort is required to reduce the considerable disparity in both mortality and illness burden.

\section{References}

1. Brown S, Kim M, Mitchell C, et al. Twenty-five year mortality of a community cohort with schizophrenia. Br J Psychiatry 2010;196:116-21.

2. Wang H, Dwyer-Lindgren L, Lofgren KT, et al. Age-specific and sex-specific mortality in 187 countries, 1970-2010: a systematic analysis for the Global Burden of Disease Study 2010. Lancet 2012;380:2071-94.

3. De Hert M, Correll CU, Bobes J, et al. Physical illness in patients with severe mental disorders. I. Prevalence, impact of medications and disparities in health care. World Psychiatry 2011;10:52-77.

4. Laursen TM, Nordentoft M, Mortensen PB. Excess early mortality in schizophrenia. Annu Rev Clin Psychol 2014;10:425-48.

5. Saha S, Chant D, McGrath J. A systematic review of mortality in schizophrenia: Is the differential mortality gap worsening over time? Arch Gen Psychiatry 2007; 64:1123-31.

6. Walker ER, McGee RE, Druss BG. Mortality in mental disorders and global disease burden implications: a systematic review and meta-analysis [published errata in JAMA Psychiatry 2015;72:736 and JAMA Psychiatry 2015;72:1259]. JAMA Psychiatry 2015;72:334-41.

7. Newman SC, Bland RC. Mortality in a cohort of patients with schizophrenia: a record linkage study. Can J Psychiatry 1991;36:239-45.

8. Olfson M, Gerhard T, Huang C, et al. Premature mortality among adults with schizophrenia in the United States. JAMA Psychiatry 2015;72:1172-81.

9. Ösby U, Correia N, Brandt L, et al. Time trends in schizophrenia mortality in Stockholm County, Sweden: cohort study. BMJ 2000;321:483-4.

10. Lawrence D, Hancock KJ, Kisely S. The gap in life expectancy from preventable physical illness in psychiatric patients in Western Australia: retrospective analysis of population based registers. BMJ 2013;346:f2539.

11. Hoang U, Stewart R, Goldacre MJ. Mortality after hospital discharge for people with schizophrenia or bipolar disorder: retrospective study of linked English hospital episode statistics, 1999-2006. BMJ 2011;343:d5422.

12. Wahlbeck K, Westman J, Nordentoft M, et al. Outcomes of Nordic menta health systems: life expectancy of patients with mental disorders. Br J Psychiatry 2011;199:453-8.

13. Gissler M, Laursen TM, Ösby U, et al. Patterns in mortality among people with severe mental disorders across birth cohorts: a register-based study of Denmark and Finland in 1982-2006. BMC Public Health 2013;13:834.

14. Gissler M, Ösby U, Westman J, et al. Mortality trends among people with schizophrenia, bipolar disorder and depression, Sweden 1987-2010. Eur J Public Health 2015;25(Suppl 3):268.

15. Kurdyak $P$, Lin $E$, Green $D$, et al. Validation of a population-based algorithm to detect chronic psychotic illness. Can J Psychiatry 2015;60:362-8.

16. Saarni SI, Viertiö S, Perälä J, et al. Quality of life of people with schizophrenia bipolar disorder and other psychotic disorders. Br J Psychiatry 2010;197: 386-94.

17. Murray RM, Sham P, Van Os J, et al. A developmental model for similarities and dissimilarities between schizophrenia and bipolar disorder. Schizophr Res 2004; 71:405-16.

18. De Hert M, Dekker JM, Wood D, et al. Cardiovascular disease and diabetes in people with severe mental illness position statement from the European Psychiatric Association (EPA), supported by the European Association for the Study of Diabetes (EASD) and the European Society of Cardiology (ESC). Eur Psychiatry 2009;24:412-24.

19. Loranger AW. Sex difference in age at onset of schizophrenia. Arch Gen Psychiatry 1984;41:157-61.

20. Manual of the international statistical classification of diseases, injuries and causes of death. 9th rev. Geneva: World Health Organization; 1992.

21. Ahmad OB, Boschi-Pinto C, Lopez AD, et al. Age standardization of rates: a new WHO standard. Geneva: World Health Organization; 2001.

22. Schizophrenia. In: A report on mental illnesses in Canada. Ottawa: Health Canada 2002:49-58. 
23. Data quality, concepts and methodology: 2. Health status indicators based on vital statistics (Statistics Canada). In: Health indicators. Ottawa: Statistics Canada; 2016. Cat no. 82-221-XWE2007001. Available: www.statcan.gc. ca/pub/82-221-x/2013001/quality-qualite/qua2-eng.htm (accessed 2016 July 6).

24. Health indicators 2012. Ottawa: Canadian Institute for Health Information; 2012. Available: https://secure.cihi.ca/free_products/health_indicators_2012 _en.pdf (accessed 2016 July 1).

25. Butler-Jones D. The Chief Public Health Officer's report on the state of public health in Canada, 2014: public health in the future. Ottawa: Public Health Agency of Canada; 2014.

26. Compton MT, Daumit GL, Druss BG. Cigarette smoking and overweight/obesity among individuals with serious mental illnesses: a preventive perspective. Harv Rev Psychiatry 2006;14:212-22.
27. Montejo AL. The need for routine physical health care in schizophrenia. Eur Psychiatry 2010;25(Suppl. 2):S3-5.

28. Tiihonen J, Lonnqvist J, Wahlbeck K, et al. 11-year follow-up of mortality in patients with schizophrenia: a population-based cohort study (FIN11 study). Lancet 2009;374:620-7.

29. Lambert TJ, Velakoulis D, Pantelis C. Medical comorbidity in schizophrenia. Med J Aust 2003;178(Suppl):S67-70.

30. Heald A. Physical health in schizophrenia: a challenge for antipsychotic therapy. Eur Psychiatry 2010;25(Suppl 2):S6-11.

31. Osborn DP, Baio G, Walters K, et al. Inequalities in the provision of cardiovascular screening to people with severe mental illnesses in primary care: cohort study in the United Kingdom THIN Primary Care Database 2000-2007. Schizophr Res 2011;129:104-10.

\section{Competing interests: None declared.}

This article has been peer reviewed.

Affiliations: Institute for Clinical Evaluative Sciences (Gatov, Rosella, Chiu, Kurdyak); Dalla Lana School of Public Health (Rosella, Chiu), University of Toronto; Institute for Mental Health Policy Research (Kurdyak), Centre for Addiction and Mental Health, Toronto, Ont.

Contributors: Evgenia Gatov, Laura Rosella and Paul Kurdyak were responsible for the conception and design of this study. Evgenia Gatov analyzed the data and interpreted the results, with assistance from Maria Chiu and Paul Kurdyak. Evgenia Gatov drafted the manuscript. All of the authors critically revised the manuscript for important intellectual content, gave final approval of the version to be published and agreed to be accountable for all aspects of the work.
Funding: This study was supported by the Institute for Clinical Evaluative Sciences (ICES), which is funded by an annual grant from the Ontario Ministry of Health and Long-Term Care (MOHLTC). It was also supported by a Menta Health and Addictions Scorecard and Evaluation Framework grant from the MOHLTC. Laura Rosella is supported by a Canada Research Chair in Population Health Analytics. Paul Kurdyak received operational grant funding from the MOHLTC Health Services Research Fund Capacity Award, and is supported in part by the Medical Psychiatry Alliance, a collaborative health partnership of the University of Toronto, the Centre for Addiction and Mental Health, the Hospital for Sick Children, Trillium Health Partners, the MOHLTC and an anonymous donor.

Acknowledgements: The authors thank Alexander Kopp, Stephanie Cheng and Andrew Calzavara for their contributions to the data analysis.
Disclaimer: This study was supported by the Institute for Clinical Evaluative Sciences (ICES), which is funded by an annual grant from the Ontario Ministry of Health and LongTerm Care (MOHLTC). The opinions, results and conclusions reported in this paper are those of the authors and are independent from the funding sources. No endorsement by ICES or the Ontario MOHLTC is intended or should be inferred. Parts of this material are based on data compiled and provided by Statistics Canada and the Canadian Institute for Health Information (CIHI). However, the analyses, conclusions, opinions and statements expressed herein are those of the authors and are not necessarily those of Statistics Canada or $\mathrm{ClHI}$.

Correspondence to: Paul Kurdyak, Paul. Kurdyak@camh.ca 